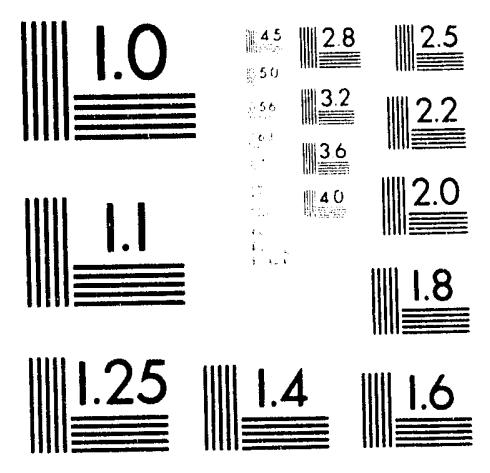



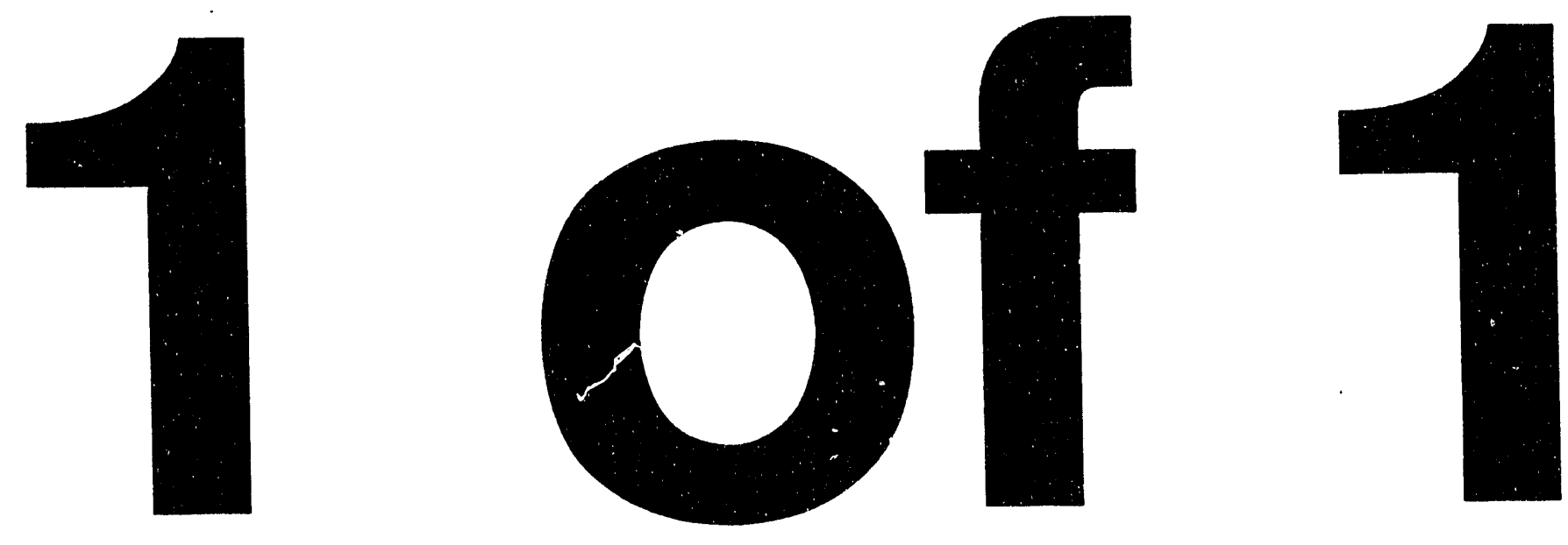
LBL-34278

\title{
IMPLANTATION OF CARBON IN GaAs AND COMPENSATING NATIVE DEFECTS
}

\author{
AMY J. MOLL, JOEL W. AGER III, KIN MAN YU, WLADEK WALUKIEWICZ, AND \\ EUGENE E. HALLER \\ Materials Science and Mineral Engineering Department \\ University of California \\ and \\ Center for Advanced Materials \\ MATERIALS SCIENCES DIVISION \\ Lawrence Berkeley Laboratory \\ University of California \\ Berkeley, California 94720
}

JULY 1993

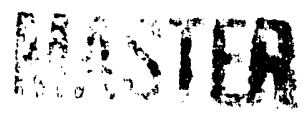

This work was supported by the Director, Office of Energy Research, Office of Basic Energy Sciences, Materials Sciences Division, of the U.S. Department of Energy under Contract No. DE-AC03-76SF00098. 


\title{
IMPLANTATION OF CARBON IN GaAS AND COMPENSATING NATIVE DEFECTS
}

\author{
AMY J. MOLL ${ }^{1,2}$, JOEL W. AGER III ${ }^{1}$, KIN MAN YU' ${ }^{1}$, WLADEK WALUKIEWICZ ${ }^{1}$, AND \\ EUGENE E. HALLER 1,2 \\ 1) Center for Advanced Materials, Lawrence Berkeley Laboratory, Berkeley, CA 94720 USA \\ 2) Materials Science and Mineral Engineering Department, University of California, Berkeley, CA \\ 94720 USA
}

Key words: Implantation, GaAs, Native defects, compensation

\begin{abstract}
The effects of co-implantation on the electrical activity of $\mathrm{C}$ acceptors have been studied using a series of elements as co-implants. A variety of electrical and structural techniques were used for characterization. It is found that although co-implantation with heavy ions improves the substitutionality of $\mathrm{C}$ atoms on As sites, a high electrical activity of the $\mathrm{C}_{\mathrm{As}}$ acceptors is attained only if the stoichiometry is maintained through co-implantation of group III atoms.
\end{abstract}

\section{INTRODUCTION}

Ion implantation has evolved into the standard doping technolugy in the semiconductor industry. Its principal advantages are the control of the doping profile and the large variety of dopant species. In elemental semiconductors such as $\mathrm{Ge}$ and $\mathrm{Si}$, activation of implanted dopants is a relatively straightforward process. In general, once the implanted ion occupies a substitutional site, it is an electrically active dopant. However, in compound semiconductors the activation of implanted dopants is more complicated.

In a compound semiconductor, the implanted ions are expected to occupy one sublattice exclusively. Consider $\mathrm{C}$ implanted into GaAs. $\mathrm{C}$ is a group IV element and occupies an As site, acting as an acceptor. Native defects associated with the non-stoichiometry due to the excess of As or deficiency of $\mathrm{Ga}$ are present in the implanted layer. These native defects can compensate the implanted dopants or passivate the dopants by forming complexes with the implanted ions. In both cases, the number of free carriers is reduced, resulting in less than $100 \%$ activation of implanted $\mathrm{C}$ ions.

Co-implantation of a complementarv species to maintain the stoichiometry of an implanted layer in compound semiconductors was onginally suggested by Heckingbottom and Ambridge.[1] In the case of $\mathrm{C}$ implanted into $\mathrm{GaAs}, \mathrm{Ga}$ is co-implanted with an energy and dose chosen to match the profile of the implanted $\mathrm{C}$ ions. The stoichiometry of the implanted layer is then maintained during the implantation and annealing processes resulting in fewer native defects which can compensate or passivate the $\mathrm{C}$ acceptors.

$\mathrm{C}$ is an excellent p-type dopant in GaAs. Its diffusion coefficient is significantly lower[2] than that of group II p-type dopants such as $\mathrm{Mg}$ and $\mathrm{Zn}$.[3, 4] Ultra-high doping levels $\left(p>10^{20} \mathrm{~cm}^{-3}\right.$ ) have been attained with epitaxial growth. $[5,6]$ However, implantation of $C$ is not as successful. Implanted alone, activation of $\mathrm{C}$ is less than $10 \% .[7,8]$ With a $\mathrm{Ga}$ co-implant, activation can increase significantly,[9] as high as 65\%.[10].

The mechanism by which the $\mathrm{Ga}$ co-implant increases the activation of $\mathrm{C}$ is unclear. Although the Ga co-implant mairitains the stoichiometry of the implanted layer, it also increases the amount of radiation damage to the substrate. $\mathrm{C}$ has an atomic mass of 12 and when implanted 
into GaAs causes little lattice damage. The concentration of defects is further reduced by selfannealing during the room temperature implantation process. The $\mathrm{Ga}$ co-implant causes considerably more damage to the substrate, increasing the number of As vacancies available for the implanted $\mathrm{C}$ ions. Co-implantation with heavy inert atoms ( $\mathrm{Ar}$ and $\mathrm{Kr}$ ) has been shown to increase the activation of $\mathrm{Si}$ in GaAs [11] and $\mathrm{C}$ in GaAs.[12] Therefore both increasing the radiation damage and maintaining the stoichiometry of the substrate increase the activation of implanted $\mathrm{C}$ in GaAs.

In this paper, we report on our studies of the effects of stoichiometry and damage and the role of native defects on $\mathrm{C}$ activation in GaAs. A series of different co-implant ions were used: $\mathrm{B}$, $\mathrm{N}, \mathrm{Al}, \mathrm{P}, \mathrm{Ar}, \mathrm{Ga}, \mathrm{As}$, and $\mathrm{Kr}$. The group III elements (B, Al, and $\mathrm{Ga}$ ) help to maintain the stoichiometry of the implanted region. The noble gasses (Ar and $\mathrm{Kr}$ ) should not affect the stoichiometry while the group $\mathrm{V}$ elements (N, P, and As) create even larger deviations in stoichiometry than implantation of $\mathrm{C}$ alone. As the atomic mass of the co-implant species increases, the radiation damage density in the substrate due to the implantation process increases. This increase is due to the larger mass of the implanted ion and the higher implantation energy required to match the $\mathrm{C}$ ion implantation profile.

\section{EXPERIMENTAL}

Semi-insulating (100) LEC GaAs substrates were solvent cleaned, etched in $12 \mathrm{M} \mathrm{HCl}$ for 1 minute, and rinsed in de-ionized water before implantation. Singly ionized $\mathrm{C}$ ions were implanted into all of the substrates simultaneously at an energy of $40 \mathrm{keV}$ and a dose of $5 \times 10^{14} \mathrm{~cm}^{-2}$. Following implantation of $\mathrm{C}$, the co-implant was performed for individual samples. The dose and energy of the co-implant were chosen to match the profile of the $\mathrm{C}$ ions as calculated by the LSS theory.[13] The wafers were tilted $7^{\circ}$ off the [100] axis during both implantations to prevent channeling. The substrates were held at room temperature during implantation. Following implantation, the samples were annealed in flowing forming gas $(90 \%$ $\mathrm{N}_{2} / 10 \% \mathrm{H}_{2}$ ) at $950{ }^{\circ} \mathrm{C}$ for 10 seconds using a proximity cap.

Alloyed contacts of In: $\mathrm{Zn}$ were formed at $250^{\circ} \mathrm{C}$ on $8 \times 8 \mathrm{~mm}^{2}$ pieces of each sample. Carrier concentration, mobility, and resistivity as a function of temperature were determined by van der Pauw geometry Hall effect measurements. The activation (or electrical activity) is then determined by dividing the sheet free carrier concentration (holes) by the implanted dose.

The amount of structural damage caused by the implantation was characterized by channeling Rutherford backscattering spectrometry (RBS) using $1.95 \mathrm{MeV} \mathrm{He}{ }^{+}$ions aligned along the $\langle 111\rangle$ or $\langle 110\rangle$ direction. Photoluminescence measurements of optically active deep levels were made at $4 \mathrm{~K}$ using the $488 \mathrm{~nm}$ line of an Ar laser.

The relative concentrations of $\mathrm{C}_{\mathrm{As}}$ were determined with local vibrational mode (LVM) Raman spectroscopy. The LVM of $\mathrm{C}_{\mathrm{As}}$ has been observed previously by Raman spectroscopy at $583 \mathrm{~cm}^{-1}$ at $77 \mathrm{~K}$. [14] Raman spectra were collected with $2 \mathrm{~cm}^{-1}$ resolution at room temperature

in the $z(x, y) \bar{z}$ pseudo-backscattering geometry. The $488 \mathrm{~nm}(2.54 \mathrm{eV})$ line of an Ar ion laser was used. The laser power was $250 \mathrm{~mW}$ and typical integration times were 1 hour. The intensity of the $C_{A s} L V M$ peak observed at $580 \mathrm{~cm}^{-1}$ below the Ar ion laser line was internally calibrated by ratioing the peak height to that of the 2 nd-order phonon observed at $52.5 \mathrm{~cm}^{-1}$.

\section{RESULTS AND DISCUSSION}

In figure 1, the sheet free hole concentration is plotted as a function of the depth of the amorphous layer due to implantation. The depth of the amorphous layer is determined by channeling RBS. As the radiation damage in the implanted layer increases, the activation of the 
implanted carbon increases. In addition, the chemical nature of the co-implant species has an effect. The highest activation levels are attained for the co-implants which are group III elements,

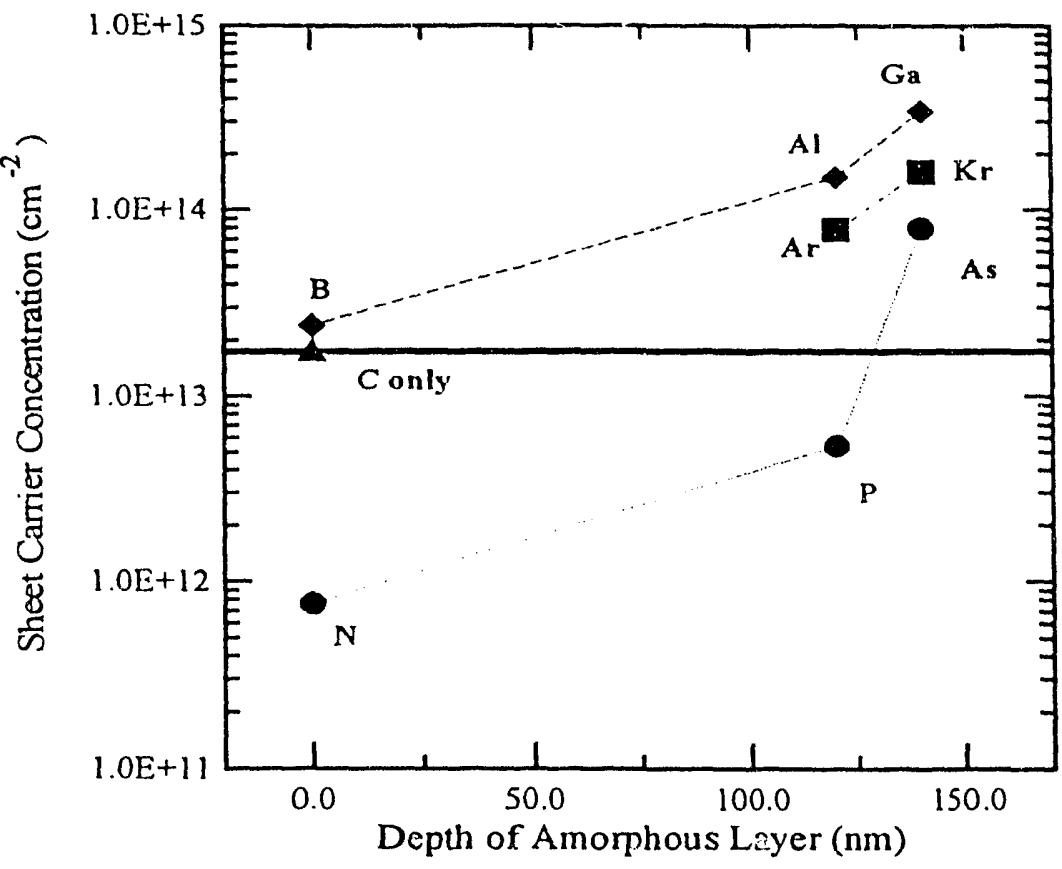

Figure 1. The sheet free hole concentration as measured by Hall effect is plotted as a function of the depth of the amorphous layer due to implantation as measured by RBS.

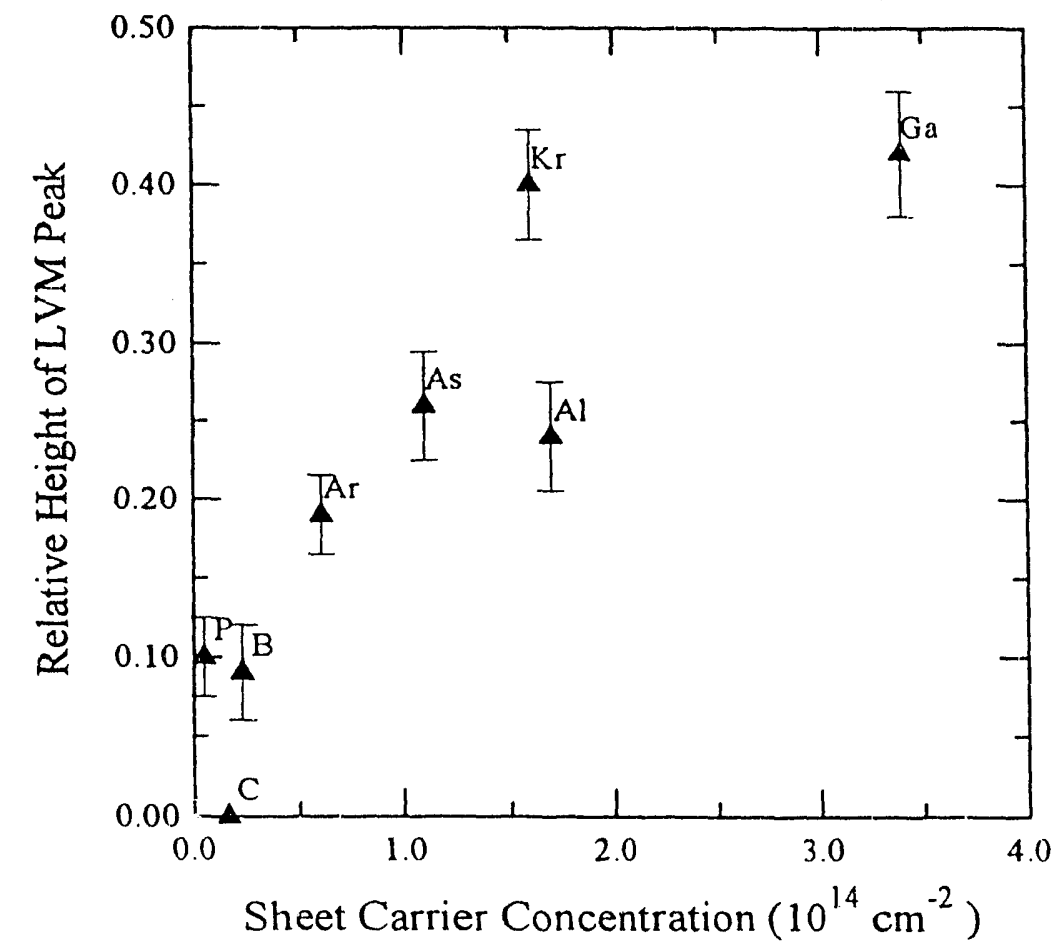

Figure 2. The relative height of $C_{A s}$ LVM peak as measured by Raman spectroscopy as a function of the sheet carrier concentration. followed by the group VIII elements. The lowest activation levels are obtained for the group $\mathrm{V}$ co-implants.

The height of the $\mathrm{C}_{\mathrm{As}}$ local vibrational mode peak as measured by Raman spectroscopy is plotted as a function of the sheet carrier concentration in figure 2. The sheet carrier concentration is not proportional to the concentration of $\mathrm{C}_{\mathrm{As}}$. Comparing group III co-implants with group VIII co-implants and considering the RBS results, samples with similar amounts of radiation damage result in similar concentrations of $\mathrm{C}_{\text {As. }}$. However for co-implants of $\mathrm{Al}$ and $\mathrm{Ga}$, the carrier concentration is significantly higher than for samples co-implanted with Ar and $\mathrm{Kr}$, respectively.

Our low temperature Hall effect and photoluminescence measurements suggest that in the samples co-implanted with Ar or $\mathrm{Kr}$, a portion of the $\mathrm{C}_{\mathrm{As}}$ acceptors are compensated. As shown in figure 3 , the $\mathrm{C}+\mathrm{Kr}$ sample has lower Hall mobilities at all temperatures than the $\mathrm{C}+\mathrm{Al}$ sample. Since the two samples have the same number of free carriers, the lower mobility indicates greater ionized impurity scattering due to compensating defects. The photoluminescence results shown in figure 4 further corroborate the existence of compensating defects. The deep defect related photoluminescence is more intense in the $\mathrm{C}+\mathrm{Kr}$ and $\mathrm{C}+\mathrm{Ar}$ (not shown) samples than in the $\mathrm{C}+\mathrm{Al}$ and $\mathrm{C}+\mathrm{Ga}$ (not shown) 


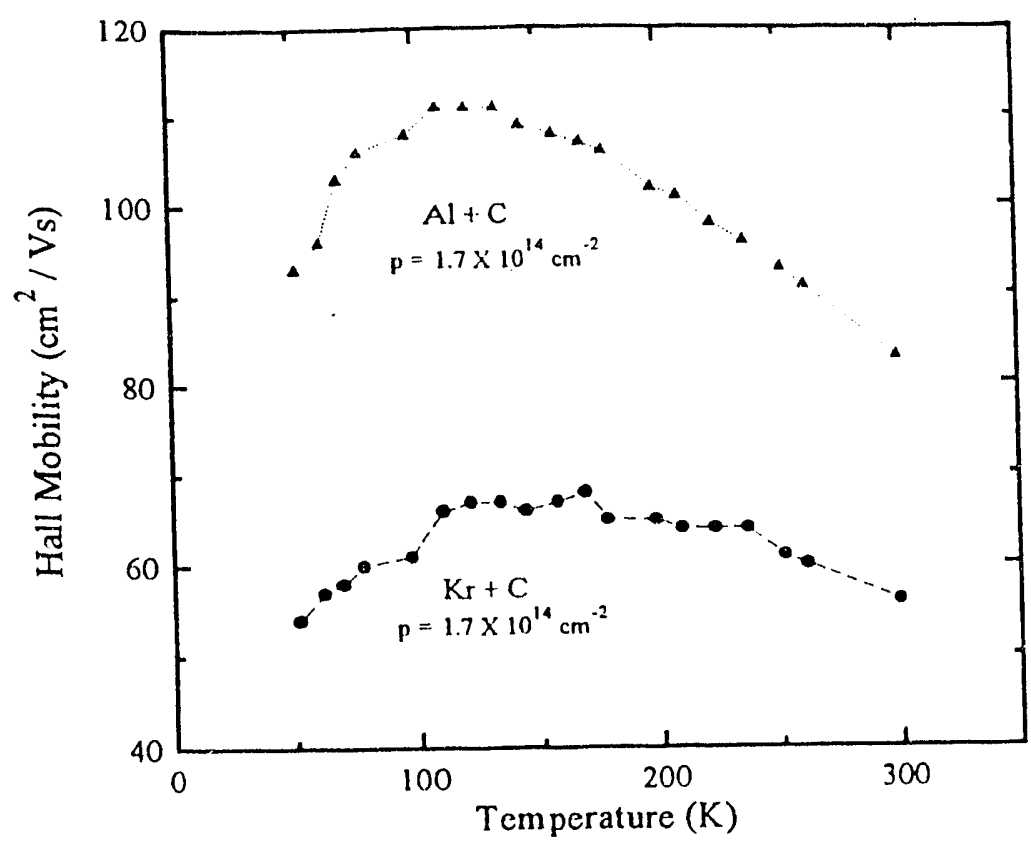

Figure 3. The Hall mobility of the free holes as a function of temperature for the $\mathrm{Al}+\mathrm{C}$ and $\mathrm{Kr}+\mathrm{C}$ samples.

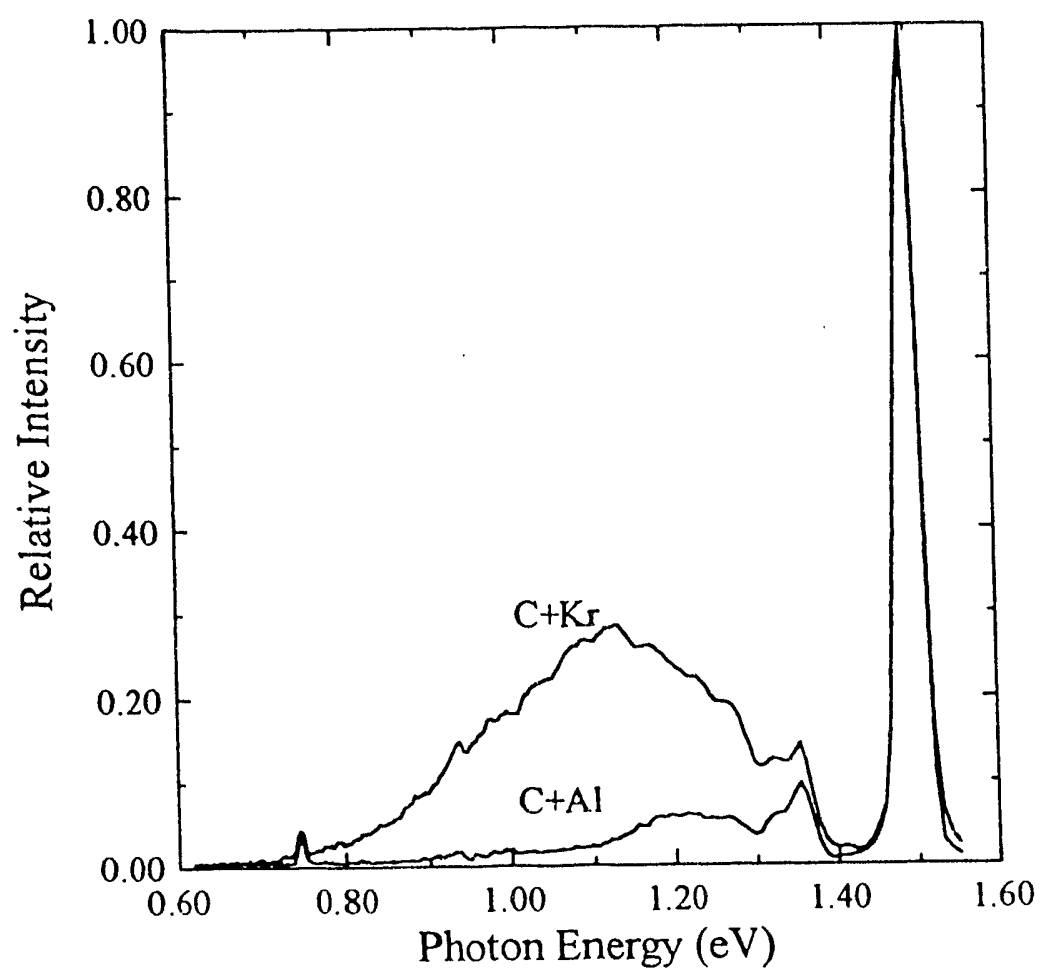

Figure 4. Relative intensity of photoluminescence as a function of photon energy for the $\mathrm{C}+\mathrm{Kr}$ and $\mathrm{C}+\mathrm{Al}$ samples. samples. In the $\mathrm{C}+\mathrm{Ar}$ and $\mathrm{C}+\mathrm{Kr}$ samples, the deviation from stoichiometry, i.e., the excess As atoms from the sites substituted by $\mathrm{C}$, is accommodated by point or extended defects. As proposed by Walukiewicz[15] in p-type GaAs the defects related to the nonstoichiometry are predominantly donors. Such donor defects can act as compensating centers reducing the free hole concentration.

The group $\mathrm{V}$ co-implants (As and P) lead to lower free hole concentrations than the group III and group VIII co-implants of similar atomic mass. In addition, the LVM peaks are smaller indicating the concentration of $\mathrm{C}_{\mathrm{As}}$ is also reduced. This reduction results from the competition of the As and $\mathrm{P}$ co-implants with the $\mathrm{C}$ for As vacancies. As and $F$ also introduce additional nonstoichiometry into the crystal increasing the concentration of native defects and further reducing the number of free carriers.

Of particular interest is the sample co-implanted with $B$. The B co-implant causes little additional radiation damage in the substrate but should help maintain the stoichiometry in the implanted layer. However the free carrier concentration is nearly the same as in the sample implanted with $\mathrm{C}$ only. This result indicates that additional radiation damage is required to increase the activation of implanted $\mathrm{C}$. 


\section{CONCLUSIONS}

Co-implantation increases the activation of implanted $\mathrm{C}$ in GaAs by two mechanisms: increasing the radiation damage in the substrate and maintaining the stoichiometry in the implanted layer. The additional radiation damage due to the heavy co-implant species provides vacant As sites for the implanted $\mathrm{C}$. Co-implants which cause similar amounts of damage to the substrate, i.e., co-implants with similar atomic weights, have similar concentrations of $\mathrm{C}_{\mathrm{As}}$. However this condition is not sufficient to obtain high concentrations of free holes. The native defects resulting from the implantation process compensate the $\mathrm{C}_{A s}$ acceptors except in the case of group III co-implants which help maintain the stoichiometry of the crystal. The highest activation attained is $65 \%$ for the case in which $\mathrm{Ga}$ is used as the co-implant.

\section{ACKNOWLEDGMENTS}

The authors would like to thank Kevin Roderick for his technical assistance in implantation and John Madok and Nancy Haegel of the University of California at Los Angeles for their help with the photoluminescence studies. This work was supported by the Director, Office of Energy Research, Office of Basic Energy Sciences, Materials Science Division of the U.S. Department of Energy under Contract No. DE-AC03-76SC00098. A.J. Moll is supported by the Robert N. Noyce Memorial Fellowship from the Intel Foundation.

\section{REFERENCES}

1) Heckingbottom, R. and Ambridge, T.: Radiat. Eff., 1973, 17, 31

2) Cunningham, B.T., Guido, L.J., Baker, J.E., Major, J.S., Jr., Holonyak, N., Jr. and Stillman, G.E.: Appl. Phys. Lett., 1989, 55, 687

3) Enquist, P., Hutchby, J.A. and de Lyon, T.J.: J. Appl. Phys., 1988, 60,4485

4) Robinson, H.G., Deal, M.D. and Stevenson, D.A.: Appl. Phys. Lett., 1990, 56, 554

5) Hanna, M.C., Lu, Z.H. and Majerfeld, A.: Appl. Phys. Lett., 1991, $\underline{58}, 164$

6) Yamada, T., Tokumitsu, E., Saito, K., Akatsuka, T., Miyauchi, M., Konagai, M. and Takahashi, K.: J. Cryst. Growth, 1989, 95, 145

7) Harris, J.S., in International Conference on Ion Implantation in Semiconductors, edited by I. Ruge and J. Graul (Springer, Berlin, 1971), p. 157.

8) Sansbury, J.D. and Gibbons, J.F.: Radiat. Eff., 1970, 6, 269

9) Pearton, S.J. and Abernathy, C.R.: Appl. Phys. Lett., 1989, 55, 678

10) Moll, A.J., Yu, K.M., Walukiewicz, W., Hansen, W.L. and Haller, E.E.: Appl. Phys. Lett., $1992, \underline{60}, 2383$

11) Liu, S.G., Narayan, S.Y., Magee, C.W. and Wu, C.P.: Appl. Phys. Lett., 1982, 41, 72

12) Moll, A.J., Walukiewicz, W., Yu, K.M., Hansen, W.L. and Haller, E.E.: Mater. Res. Soc. Proc., 1992, 240, 811

13) Lindhard, J., Scharff, M. and Schiott, H.E.: Kfl. Danske. Videnskab. Selskab. Mat.-Fys. Medd., 1963, 33

14) Wagner, J., Maier, M., Lauterbach, T., Bachem, K.H., Fischer, A., Ploog, K., Mirsh, G. and Kamp, M.: Phys. Rev. B, 1992, 45, 9120

15) Walukiewicz, W.: Appl. Phys. Lett., 1989, 54, 2094 

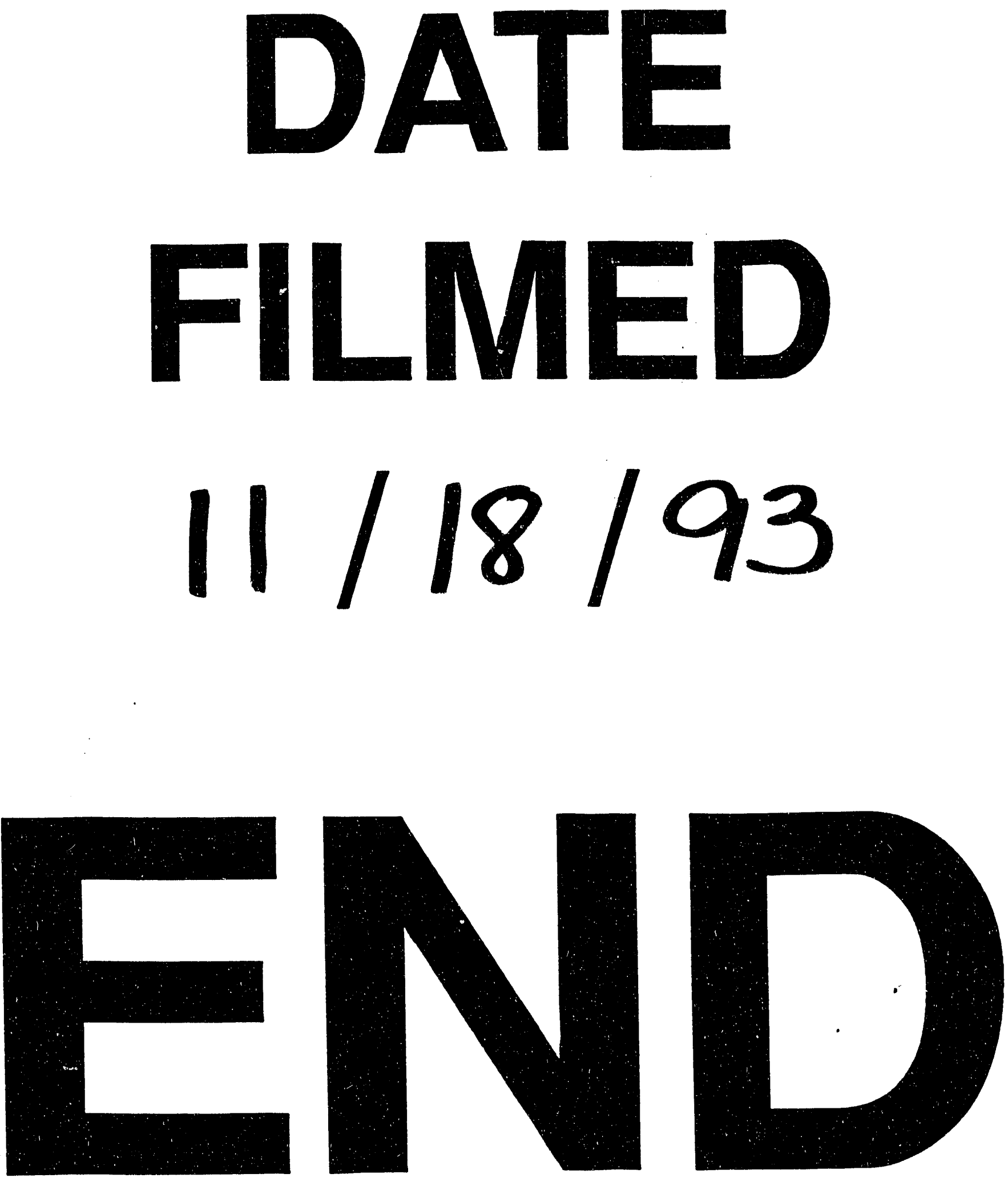
